\title{
Quantitative Identification of Reservoir Fluid Properties and Boundary Shifts by Laser-induced Fluorescence
}

\author{
JiN SU ${ }^{1 *}$, SHUICHANG ZHANG ${ }^{1}$, YU FANG ${ }^{1}$ \\ ${ }^{1}$ Research Institute of Petroleum Exploration and \\ Development, PetroChina, Beijing 100083, China
}

It is of theoretical and practical significance for hydrocarbon exploration to reconstruct hydrocarbon migration and adjustment by reinforcing geochemical quantitative studies on reservoirs. In a reservoir with multi-stage structural movement, both hydrocarbons and reservoir bitumen may have suffered from multi-stage mixture, alteration and deconstruction, which results in difficulties to reconstruct migration and adjustment histories of hydrocarbons due to many factors that affect the reconstruction. However, direct evidence for different phases of hydrocarbon migration, variations in hydrocarbon properties and shifts of oil-water boundaries could be obtained from fluid inclusions in the reservoirs, which could record primary components and temperaturepressure conditions of hydrocarbon migration and charge. Thus, the present study uses quantitative assessment parameters, such as fluorescence strength and maximum emission waves of organic fluid inclusions, to characterize variations related with oils, gases and water in reservoirs so as to reconstruct adjustment processes of hydrocarbon reservoirs.

The Tarim Basin in China has experienced multi-cycle structural activities, and several developed petroleum systems are vertically superimposed or horizontally distributed in the basin. Median-size grains were screened from these various sandstones including water-bearing sandstone, sandstone with different abundance of oil-bearing inclusions and condensate-bearing sandstone. It is concluded that the relationship of variations in oil, gas and water boundaries of this oilbearing layer system is apparently of regional division. 